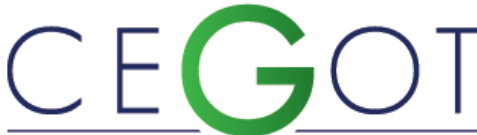

Centro de Estudos de Geografia e Ordenamento do Território
BARTOLI, ESTEVAN

Universidade do estado do Amazonas - Centro de Estudos Superiores de

Parintins

69.152-470 / Parintins - AM

ebartoli11@gmail.com

\title{
Cidades pequenas na Amazônia: sítio, situação e sistemas territoriais de Barreirinha (AM).
}

Small cities in the amazon: place, situation and the territorial systems in Barreirinha (AM).

Referência: Bartoli, Estevan (2020). Cidades pequenas na Amazônia: sítio, situação e sistemas territoriais de Barreirinha (AM). Revista de Geografia e Ordenamento do Território (GOT), no 19 (junho). Centro de Estudos de Geografia e Ordenamento do Território, p. 132-157, dx.doi.org/10.17127/got/2020.19.006

\section{RESUMO}

O objetivo do artigo é caracterizar Barreirinha (AM) enquanto cidade pequena, descrevendo a gênese urbana, funções e aspectos do sítio que condicionam sua situação: polarização junto à metrópole Manaus e Parintins (considerada cidade média), e a ampliação de relações com distritos e comunidades de sua hinterlândia. Constata-se que os fluxos são condicionados por duas calhas de rios, Andirá e Paraná do Ramos. A partir da aplicação do modelo analítico STUR (Sistemas Territoriais Urbano-Ribeirinhos), averiguou-se os papéis das redes de sujeitos locais e suas articulações via transporte fluvial, identificando um padrão de organização territorial com intensa dinâmica de sistemas territoriais ribeirinhos e fluviais no baixo Amazonas.

Palavras chave: Cidade pequena; Sítio; Situação; Sistemas territoriais.

\section{ABSTRACT}

The aim of this paper is to characterize Barreirinha (AM) as a small town, describing your urban genesis, your functions, your roles and aspects of the site that condition your situation: polarization with the metropolis Manaus and Parintins (considered a middle city), and the expansion of relations with districts and communities of your hinterland. It was verified that the flows are conditioned by two river channels, Andirá and Paraná do Ramos. As from the application of the analytical model URTS (Urban-Riverside Territorial Systems), the roles of local subject networks and their articulations via river transport were investigated, identifying a pattern of territorial organization with intense dynamics of riverine and riverine territorial systems in the lower river of Amazons.

Keywords: Small Town; Site; Situation; Territorial systems. 


\section{INTRODUÇÃO}

O presente artigo pretende contribuir para a construção de um modelo analítico que construa leitura mais completa sobre o fenômeno urbano na Amazônia, propiciando entendimento relativo à composição, papeis e funções urbanas de cidades com intensas dinâmicas ribeirinhas e com redes urbanas primordialmente fluviais.

A coleta de dados corresponde à primeira fase de estudos sobre os municípios do baixo Amazonas no Projeto intitulado Rede urbana, Tipologia de Cidades e Sistemas Territoriais Urbano-ribeirinhos no Baixo Amazonas ${ }^{1}$, dando sequência à proposta metodológica presente em Bartoli (2017, 2018a, 2018b).

Avanços recentes na proposição de tipologias das cidades da Amazônia Ocidental (Schor, et al, 2016), resultaram no entendimento dos papéis de Parintins enquanto cidade média de responsabilidade territorial (Schor e Oliveira, 2016; Bartoli et al, 2019), surgindo lacunas explicativas sobre os papéis e funções das cidades menores que orbitam sobre sua região de influência e, obviamente, sob influência das metrópoles regionais Manaus e Belém, assim como da rede urbana paraense.

No primeiro subitem, retomamos aportes teóricos para construção de uma concepção crítica dos papéis que cidades pequenas na Amazônia desempenham, ressaltando que estão inseridas num processo de produção desigual dos espaços urbano-regionais (mesmo considerando as baixas interações com redes urbanas nacionais), sujeitas à competição inter-regional que condiciona a baixa dinâmica econômica desses municípios.

No segundo momento, discutimos aspectos contextuais e geo-históricos de sítio e da situação de Barreirinha, refletindo sobre o reposicionamento da cidade em sua função de lugar central na rede urbana sub-regional, considerando os condicionantes geomorfológicos na dinâmica dos fluxos de navegação da cidade. A periodização espacial nos indica alteração dos papeis e funções de Barreirinha sendo polarizada por Parintins.

A escolha das escalas, portanto, é imprescindível para não incorrermos em diagnósticos fragmentários, parciais ou estáticos de como a rede urbana de Barreirinha está inserida no

\footnotetext{
${ }^{1}$ Financiamento concedido através de Bolsa Produtividade da Universidade do Estado do Amazonas (UEA) intitulado: Rede urbana, Tipologia de Cidades e Sistemas territoriais Urbano-ribeirinhos no Baixo Amazonas.
} 
contexto sub-regional. Para isso, materiais, métodos de pesquisa e critérios de análise sobre os fluxos de Barreirinha são apresentados na terceira seção sobre o modelo STUR (Sistemas territoriais Urbano-ribeirinhos). O modelo STUR propicia apreensão da densidade de relações que cidades possuem com seus entornos a partir das pesquisas realizadas em Parintins (Bartoli, 2017, 2018a; 2018b). Os resultados apresentados demonstram a existência de um padrão espacial de influência da cidade no contexto sub-regional (com intensa dinâmica ribeirinha e fluvial ${ }^{2}$ ), estruturado por sistemas territoriais populares em interação com sistemas territoriais mercantis. Sítio e situação atrelados às características das calhas de rios são aspectos essenciais no entendimento da rede.

\section{Cidades Pequenas, Relações Escalares e o Contexto Sub-Regional}

Refletir sobre o fenômeno urbano na Amazônia requer retomada de aspectos teóricos que permeiam desde a gênese da rede urbana e sua inserção em ciclos de econômicos de produção/extração de mercadorias vinculadas às demandas da economia-mundo (Wallerstein, 1985), cuja valorização flutua com as transformações e reveses que a economia global impõe. Nesse sentido, Becker (2005) aponta a economia amazônica como "reflexa" desses vieses econômicos mundiais, cujos desdobramentos dessa influência global multiescalar na rede urbana tem sido objeto de estudos diversos (Trindade JR., 2010; Monte Mór, 1994; Browder; Godfrey, 2006, Becker, 2005).

A análise das cidades na Amazônia pode indicar o caráter desigual do processo de desenvolvimento capitalista. Becker (2013), afirma que o não desenvolvimento das cidades na região tem explicação na ausência de novas divisões de trabalho. Tais divisões estimulariam trocas comerciais e incentivariam a substituição de importações, possibilitando a organização da rede urbana para criação de relações mútuas entre as cidades, rompendo assim vias hierárquicas que dominam núcleos urbanos. Essa falha, presente até hoje na ausência de agregação de valor aos produtos exportados, "é uma das principais razões da insuficiência de dinamismo urbano. As pequenas manufaturas geradas logo sucumbiram com o declínio do surto (Becker, 2013 - p. 19)".

\footnotetext{
${ }^{2}$ Usaremos o termo ribeirinho associado a práticas espaciais e territorialidades associadas a populações interioranas, reproduzidas e adaptadas ao meio urbano. O termo fluvial será utilizado indicando maior funcionalidade com uso de embarcações maiores, relacionadas a transporte de cargas.
} 
A baixa capacidade histórica de complementação econômica entre as cidades, com escassas trocas mercantis e formação de economias com baixa diversidade e complexidade, já havia sido apontada por Machado (1999) em análise do período Colonial como uma "protourbanização", nos auxiliando na formulação de um dos problemas levantados em nossas pesquisas ${ }^{3}$. A maneira como esses antigos padrões de circulação e extração de excedentes podem ser interpretados frente às recentes mudanças relacionadas ao processo de urbanização é parte de uma questão ampla que se desdobram outras: Qual seria a capacidade de mediação no ordenamento territorial que tais núcleos urbanos possuem hoje? Quais são as redes de sujeitos e como suas práticas territoriais reinserem o papel dos núcleos urbanos numa nova divisão territorial do trabalho? Como hipótese, afirmamos que tais permanências são absorvidas por novas dinâmicas atreladas ao aprofundamento das relações econômicas de escalas diversas que se acirram com o processo de urbanização e da formação da rede urbana regional.

No bojo desse processo de urbanização, "a rede urbana passou a ser o meio através do qual a produção, circulação e consumo se realizam efetivamente (Corrêa, 2006, p.15)". Portanto, frentes de expansão de desenvolvimento dessas cidades se consolidaram através de "suas relações oriundas de estruturas urbanas mais antigas e sujeitas a transformações recentes" (Vicentini, 2004, p.62) tendo no caso do baixo Amazonas, condicionantes de fluxos dos transportes fluviais e das dinâmicas ribeirinhas.

Para caracterizar a mudança de padrão de organização do espaço regional e a maior complexidade nos conteúdos e formas, seja pelo papel histórico ativado e posteriormente desativado pela emersão de novas frentes, ou em cidades modernas oriundas de grandes projetos (mineração, por exemplo), surgem estudos de tipologias. Esforços teóricos para o entendimento de frentes de expansão, urbanização dirigida pela colonização particular (companhias colonizadoras), colonização oficial estatal (Becker, 1990; Vicentini, 2004), cidades ribeirinhas (Trindade Junior - 2010), ou no papel das cidades médias (Oliveira \& Schor, 2010; Schor et al. 2009; Bartoli et al, 2019), são alguns exemplos de estudos sobre a manifestação do processo urbano na região. A urbanização da fronteira regional é também caracterizada por ser desarticulada do seu próprio desenvolvimento pois "vai além dos

\footnotetext{
${ }^{3} \mathrm{O}$ presente texto compõe pesquisa em andamento atrelada à bolsa produtividade da Universidade do estado do Amazonas (UEA), com intuito de estudar os municípios que compõem a sub-região do baixo Amazonas.
} 
limites internos de crescimento que a velocidade do desenvolvimento da região pode impor" (Browder; Godfrey, 2006, p. 102).

Analisar como a base produtiva regional da maioria das cidades na Amazônia tem sido afetada, levanta o desafio de pesquisas em considerar a competição inter-regional no interior do espaço brasileiro, assim como as transformações do cenário econômico nacional/internacional. Como aponta Brandão (2007- p.159), tais pesquisas necessitam desvendar como esse amálgama entre formas atrasadas de capital e as estratégias empresariais diversas foram levadas a cabo para a preservação da riqueza patrimonial das elites nacionais ou regionais. Portanto, frente a esse cenário, há redefinição dos papeis e funções de cidades pequenas nos interiores da Amazônia que possuem relações escalares e redes de sujeitos que requerem metodologia específica, com variáveis complementares que propiciem explicações do padrão espacial das redes urbanas existentes, visando futuras propostas de desenvolvimento territorial regional. O autor faz alerta necessário tecendo crítica às recentes correntes que cultuam a maximização e potencialização do território local como estratégia de desenvolvimento, e acabam negligenciando questões estruturais, e exageram na capacidade endógena de determinado território (Brandão, 2007, p.63). Desconsideram as forças coercitivas exógenas e macroeconômicas como concorrências/rivalidades entre agentes capitalistas e forças oligopólicas, por exemplo. Esse tipo de análise incorre no erro de desconsiderar as hierarquias inter-regionais, pois o comando maior desse processo está fora dos espaços de análise "tornando-se impositivo estudar a natureza das hierarquias (impostas em variadas escalas) de geração e apropriação de riqueza" (Brandão, 2007, p. 48).

Retomando essa problemática para estudos de cidades pequenas e médias, Mello e Silva (2010) destaca que os benefícios do processo de crescimento econômico não estão sendo distribuídos de forma justa (ou equilibrada) sobre todo o espaço geográfico, salientando agravantes nas diferenças de renda per capita e da qualificação do capital humano que são acentuadas pelos desequilíbrios espaciais. A busca por equidade espacial, teoricamente, é a maximização do acesso a todos os componentes do bem-estar social por parte de uma determinada população, a partir de seus padrões espaciais (Ibid, p. 112).

Nesse contexto, o modelo analítico relativo ao Sistema Territorial Urbano-Ribeirinho (STUR) pretende preencher lacunas em pesquisas sobre os papéis de cidades na Amazônia, pois em 
cidades de dinâmica ribeirinha há dinamismo associado à formação da chamada "economia informal", que preferimos nomear como popular. A análise do STUR contribui demonstrando: que a economia urbana incompleta suscita por parte dos citadinos a manutenção de vínculos territoriais com áreas diversas do entorno das cidades (comunidades, aldeias, assentamentos, etc.); as redes locais de sujeito utilizam das oportunidades existentes na cidade para reconstrução de territorialidades (considerando dimensões políticas, culturais, econômicas e com relações com a natureza local - Bartoli, 2017); ocorre aumento da circulação sub-regional (transporte fluvial) com intensificação de complementaridades entre interiores e a cidade (Bartoli, 2018a) e esta com a metrópole Manaus e demais redes regionais e nacionais; cidades reforçam centralidades e desempenham desenvolvimento de novas formas de distribuição de produtos industrializados, consumo urbano e absorção de recursos regionais, reordenando suas áreas de influência e reconfigurando o espaço intraurbano (Bartoli, 2018b); as camadas populares do STUR ficam cada vez mais sujeitas ao domínio do capital mercantil local, incluindo relações e disputas escalares com outros municípios da rede (Bartoli, 2019).

Pela desigual capacidade de competição entre regiões, o espaço geográfico possui no processo de urbanização o nervo essencial de intermediação das relações de dominação, como apontam Santos e Silveira (2003), onde produtos mais rentáveis recebem primazia em relação a outros, causando desvalorização de certas atividades em favor de outras, inserindo uma especialização espacial. Essa especialização geográfica da produção é responsável por uma massificação do capital, que "impõe ao mercado uma escala espacial mais ampla, e pode-se tanto falar de uma alienação regional como de uma alienação do homem-produtor" (Ibid, p. 145), causando colapso em cidades locais. No estado do Amazonas, esse processo foi dinamizado pela criação da Zona Franca e a posterior criação do Polo Industrial de Manaus, que impactaram negativamente as economias de pequenas cidades interioranas.

O antigo Projeto de entreposto comercial elaborado para Manaus em 1957 foi modificado com a incursão do regime militar que desde 1967, instituindo a Superintendência da Zona Franca de Manaus (SUFRAMA), com objetivo de transformar a Zona Franca em um centro industrial (Becker, 1974; Fonseca, 1982). Essa transformação gerou mudanças espaciais na cidade de Manaus com reflexo em todo o estado, especialmente nas cidades da calha do 
Amazonas. Mesmo com boas intenções do Planejamento Estratégico da SUFRAMA em "Aprimorar o processo de interiorização dos efeitos do modelo Zona Franca de Manaus" (Relatório de Gestão SUFRAMA, 2007, p.13), as desigualdades espaciais se aprofundaram. Pretendendo "fomentar a produção no interior da região, com agregação de valores através de indústrias vinculadas que aumentem a produção, a atividade econômica e renda regional", tal quadro esteve longe de se concretizar nos municípios interioranos, como demonstra a tabela 1 , ficando latente na disparidade de população, renda e desenvolvimento humano entre a capital Manaus comparada às cidades pequenas da subregião de planejamento do baixo Amazonas $^{4}$, ou até mesmo com a seguda maior cidade do estado, Parintins.

Outras disparidades chamam atenção na Tabela 1, com o PIB per capta da capital Manaus ultrapassando o triplo do PIB de Parintins. Esgotamento sanitário é outro aspecto que demonstra o abandono das políticas públicas para os interiores.

Situado na porção oriental do Estado do Amazonas, o município de Barreirinha faz limites com os municípios de Parintins, Urucurituba, Boa Vista do Ramos, Maués e com Aveiro, no Estado do Pará. O município possui uma extensão territorial de $5.751 \mathrm{~km}^{2}$ e contava com uma população de 31.593 habitantes, perfazendo uma densidade demográfica de 4,76 $\mathrm{hab} / \mathrm{km}^{2}$ (IBGE, 2010).

Recentemente, a temática sobre cidades pequenas tem obtido destaque nos estudos urbanos, com avanços importantes na categorização de seus papéis e funções. Realizando extensa revisão bibliográfica sobre o assunto, Sposito e Jurado da Silva (2009) afirmam que as cidades pequenas oferecem o qualificativo inicial para a caracterização do urbano e da cidade porque, "[...] núcleos dessa magnitude, não apresentam dimensões populacionais muito complexas, o que permite avaliar com melhor clareza como se expressam as principais demandas da população (Ibid, p. 205)". Apontam que a cidade pequena deve ser interpretada como a marca de uma escala da dimensão de cidade na divisão territorial do trabalho e da transformação do espaço em relação dialética e contínua com a luta de classes, inserindo-se no processo reticular da desigualdade geográfica do espaço.

\footnotetext{
${ }^{4}$ Denominamos no presente texto baixo Amazonas, a sub-região de planejamento composta pelos municípios de Urucará, Boa Vista do Ramos, Barreirinha, Maués, São Sebastião do Uatumã, Nhamundá e Parintins.
} 
Mia uma vez observando a Tabela, salta aos olhos a ínfima parcela de pessoal ocupado, o que nos remete a pensar sobre a informalidade dinamizada pela economia popular, base da proposta do modelo STUR.

Tabela 1 - Comparativo das características sociodemográficas dos municípios do baixo Amazonas.

\begin{tabular}{|c|c|c|c|c|c|c|}
\hline Municípios & População & PIB per capta & $\begin{array}{l}\text { Pessoal } \\
\text { ocupado }\end{array}$ & IDH & $\begin{array}{c}\text { Mortalidade } \\
\text { infantil (óbitos } \\
\text { por mil nascidos } \\
\text { vivos) }\end{array}$ & $\begin{array}{c}\text { Esgotamento } \\
\text { sanitário } \\
\text { adequado }\end{array}$ \\
\hline Urucará & 16.383 & $17.378,65$ & 882 & 0,620 & 11,11 & 10,9 \\
\hline $\begin{array}{l}\text { Boa Vista do } \\
\text { Ramos }\end{array}$ & 18.781 & $6.089,15 \mathrm{R} \$$ & 685 & 0,565 & 12,54 & $29,7 \%$ \\
\hline Barreirinha & 31.593 & $7.059,80 \mathrm{R} \$$ & 954 & 0,574 & 14,94 & $4,3 \%$ \\
\hline $\begin{array}{l}\text { São } \\
\text { Sebastião } \\
\text { do Uatumã }\end{array}$ & 13.685 & $7.232,53$ & 536 & 0,577 & 19,42 & $1,7 \%$ \\
\hline Nhamundá & 20.899 & $6.462,02$ & 888 & 0,586 & 16,76 & 16,1 \\
\hline Maués & 62.755 & $6.481,40$ & 3.574 & 0,588 & 16,74 & 27,1 \\
\hline Parintins & 113.168 & $9.092,68$ & 6.974 & 0,658 & 22,91 & 19,3 \\
\hline Manaus & 2.145 .444 & $33.564,11$ & 505.682 & 0,737 & 14,52 & $62,4 \%$ \\
\hline
\end{tabular}

Fonte: IBGE Cidades (2019) - organizado pelo autor.

Refletindo sobre o âmbito da rede urbana brasileira, Santos (1979) aponta que nas pequenas cidades nem sempre há uma dimensão mínima requerida para instalação de conteúdos modernos, onde os consumidores que requerem produtos ou serviços raros dirigem-se às cidades maiores. Essa é uma característica que merece atenção quando tratamos de cidades pequenas na Amazônia dinamizadas por ligações fluviais, pois há maior 
distância dos grandes centros dificultando a realização dos trajetos (custos altos e baixa eficiência dos transportes fluviais). O que o autor denomina como circuito inferior, (presente onde se encontra a população pobre como nas periferias de grandes e médias cidades), é dinamizado enquanto modo de viabilizar o consumo e requer metodologia específica para cidades com dinâmicas ribeirinhas intensas e suas escalas com a rede urbana, abordados no último subitem na proposta analítica do Sistema Territorial Urbano Ribeirinho (STUR).

Em outro estudo de destaque sobre cidades pequenas, Endlich (2009, p.151) salienta que transformações culturais e de valores que permeiam e estabelecem relações sociais (e também a forma e o volume do consumo), são fatores relevantes para compreender o significado das pequenas cidades. Sinaliza ainda que a distinção cultural entre cidade e campo tende a se apagar, mas com permanências de ilhas de ruralidade em decorrência da maneira contraditória como isso ocorre, onde significativas partes do que se considera cidade são interpretadas como espaço de mediação entre campo e a cidade, cuja a expressão brasileira seriam as favelas.

Outra característica das cidades pequenas ocorre no declínio da sociedade rural que é acompanhado de mudanças no consumo, pela diminuição da produção para subsistência, onde

“[...] a passagem para a condição urbana, ainda que marcada pelas contradições, cria uma sociedade com uma alta demanda, ou repleta de necessidades a serem supridas por meio do comércio ou de serviços, acentuando fortemente a divisão social do trabalho e a financeirização das relações sociais. Dessa maneira explica-se a criação de novos padrões comerciais" (ENDLICH, p. 158)

Tais estudos de Endlich (2009) relativos ao norte paranaense, apontam que essa ampliação qualitativa e quantitativa do consumo fez com que a maioria das pequenas cidades perdesse centralidade em relação ao parâmetro do comércio existente em décadas anteriores, onde a importância do consumo para a rede urbana está na estrutura que ela exige, "já que a estruturação dessa rede diante do mesmo pode significar o desmantelamento daquela preexistente, afetando as interações espaciais, especialmente os papéis e significados das pequenas cidades." (Ibid, p.160). A autora descreve que a implantação de rodovias e autopistas com intensificação do uso de automóveis, implicou em acesso de populações a 
cidades vizinhas maiores, causando falência em comércios de pequenas cidades locais (perda de centralidade). Essas reflexões nos inspiram a averiguar como o transporte fluvial causa alterações de centralidades em cidades pequenas à exemplo de Barreirinha, e qual é o padrão do comércio existente.

Resumindo, tais aportes teóricos dialogando com nossa temática pesquisada: pelas as desigualdades acentuadas na rede urbana do Amazonas com a consolidação do modelo Polo Industrial de Manaus, há manutenção da baixa complexidade nas economias urbanas de cidades pequenas, gerando processo de densificação da economia popular informal que se reterritorializam nas cidades. Isso tem incentivado formação de novos bairros populares em cidades ribeirinhas/fluviais que incitam novas práticas no espaço para viabilizar o consumo. Como veremos, a economia popular necessita da produção rural e extrativismos diversos complementares para manutenção da vida na cidade (que incentiva a circulação constante cidade/interiores no STUR). Em cidades da Amazônia com intensa dinâmica de circulação entre bairros populares e os chamados "interiores" (comunidades de portes diversos, Terras Indígenas, Fazendas ou pequenos conjuntos de moradias), o modelo STUR obteve resultados satisfatórios na análise da economia popular de Parintins (considerada cidade média de responsabilidade territorial em Schor e Oliveira, 2016), modelo aplicado a Barreirinha.

\section{Sítio e Situação de Barreirinha: Lugares Centrais, Rede Urbana e Condicionantes Geomorfológicos na Dinâmica Da Cidade.}

$\mathrm{O}$ intuito do presente subitem é salientar que o entendimento do padrão espacial que cidades com dinâmicas ribeirinhas e fluviais estão inseridas, são necessárias considerações sobre os aspectos geomorfológicos que afetam a dinâmica das cidades. Tais fatores, no caso de Barreirinha, recondicionaram sua inserção na rede urbana sub-regional redefinindo centralidades e sua polarização com Parintins principalmente.

Por terem experimentado apenas um ou dois surtos de crescimento econômico, a maioria das cidades na Amazônia, não alteraram seus conteúdos, estrutura e complexidade, permanecendo na condição de lugares centrais, não possuindo hinterlândia organizada 
como afirma Becker (2013 - p.44-45). A autora defende que, ao contrário do estabelecido pela teoria dos lugares centrais, o processo de consolidação dessas cidades não leva à regularidade espacial da influência desses fluxos, ressaltando que aspectos naturais das cidades na Amazônia provavelmente criam localizações de núcleos dispersos, enquanto que diferenciações sociais para o comércio podem criar padrões regionais de agrupamentos de cidades.

Esse caráter irregular de assentamentos e formação de núcleos urbanos servindo de base para exploração de produtos regionais, pode estar, em diversos contextos, ligado ao tipo de produto ou ciclo produtivo de curta duração (juticultura, por exemplo). Browder e Godfrey (2006) abordam casos de áreas de extração de mogno em cidades pequenas de Rondônia que acabaram crescendo rapidamente (processo chamado pelos autores como "boom towns"), passando posteriormente por rápido declínio da população devido o esgotamento da madeira. Nos municípios que compõem o baixo Amazonas ${ }^{5}$, outros casos de ciclos de curta duração ocorreram como a extração do pau-rosa para fabricação de seivas de perfumes e o ciclo da juta, que não causaram esse rápido declínio, mas crises pontuais que incitaram que populações migrassem para outras atividades nas cidades e interiores.

Mesmo admitindo o caráter inconstante dessas atividades, tais sistemas territoriais possuem nós de ordenamento nas cidades sendo dinamizados por redes de sujeitos pertencentes à economia popular em relação densa com fortalecimento de elites locais ligadas ao capital mercantil. Demonstraremos, ao contrário do que afirma Becker (2013), que existem regularidades e que os fluxos e fixos existentes necessitam de metodologia específica para apreensão (proposta do STUR), pela composição e intensidades diferenciadas dos elementos que formam a rede urbana.

Para Mello e Silva (2010) a questão da centralidade é discutida no contexto do que poderia ser chamado de estruturação/reestruturação produtiva, retomando textos clássicos que evidenciam que cidades e as estradas criam a região, sendo, portanto, organismos que dirigem o abastecimento regional (Vidal de La Blache, 1920). No caso do Amazonas essa função é cumprida por Manaus (centros da logística regional) e Parintins (centro de logística sub-regional), além da influência dos fluxos advindos da rede urbana do Pará.

\footnotetext{
${ }^{5}$ Parintins, Barreirinha, Nhamundá, Boa Vista do Ramos, Maués, Urucará e São Sebastiao do Uatumã.
} 
O caso de Barreirinha é emblemático no que tange à consolidação de sua centralidade, pois os aspectos do sítio e condicionantes geomorfológicos das redes fluviais que entrecortam o município foram causadores de enorme diferencial em suas relações atuais, se comparados às demais redes urbanas brasileiras. No último quartel do século XIX, a sede municipal teve que ser transferida de um sítio cujos anos de secas extremas seu rio de acesso se tornava não navegável, situada na margem direita do curso médio do rio Andirá, distante $6 \mathrm{~km}$ do atual sítio. A antiga sede é chamada tualmente de distrito ${ }^{6}$ de Freguesia do Andirá (localização na figura 2).

Em 13 de maio de 1872 foi estabelecida Lei $n^{\circ} 263$ que transferiu a sede para o local denominado hoje como Barreirinha, localizado na margem direita do Paraná do Ramos (figura 2). Conforme Andrade (1960), duas justificativas impulsionaram a mudança do sítio: a primeira é o supracitado acesso ao rio Andirá na vazante que impedia que embarcações de maior calado adentrassem ao rio, dificultado o comércio local. A segunda justificativa faz referência à urgência que se tinha na época em frear a rede de contrabando pelas águas do Ramos, o que causava muitos prejuízos à economia amazonense.

Essa mudança no sítio também foi estratégica para atender necessidades por serviços das comunidades pertencentes tanto do Paraná do Ramos quanto às do rio Andirá, e redinamizou a rede de fluxos de Barreirinha com seu entorno. A nova sede no Ramos ficou melhor posicionada em relação a Parintins, Boa Vista do Ramos e Maués, não possuindo restrições sazonais de navegabilidade melhorando sua situação (figura 2). 0 termo posição designa localização física, já situação envolve outros elementos que tornam a posição um fator vantajoso, como a presença de eixos de circulação (GEORGE, 1983, p. 40). Com a mudança, Barreirinha passou estabelecer relações reticulares mais intensas tanto com a metrópole Manaus a oeste e com Parintins a leste.

Como aponta Endlich (2009) não há como estudar papéis e significados de pequenas cidades sem estudo de seu entorno, pois os papéis só podem ser compreendidos mediante a composição desse cenário. Nas últimas duas décadas, Parintins veio se consolidando enquanto cidade prestadora de serviços de saúde e educacionais (Schor e Oliveira, 2016), e

\footnotetext{
${ }^{6}$ O termo "Distrito" é utilizado neste local por meio da Lei Orgânica do Município de Barreirinha que através do Artigo 195을 afirma que só é considerado distrito todas as comunidades com uma população acima de 80 famílias e que tenham as condições básicas como escolas, posto de saúde, energia elétrica, água encanada, etc. (MESQUITA, 2013).
} 
pela rede de educação superior (Schor \& Marinho, 2013; Marinho, 2015) possuindo universidades públicas (Universidade Federal do Amazonas e Universidade do Estado do Amazonas), Instituto Federal (IFAM) e diversas outras instituições estatais (EMBRAPA, FUNAI, IDAM), além de faculdades particulares. Outro diferencial que aumentou o grau de polarização da cidade foi o fortalecimento do Festival Folclórico de Parintins, que recebe verbas milionárias tanto do Governo do Estado do Amazonas (Secretaria de Cultura), quanto de multinacionais patrocinadoras como a Coca-Cola e Petrobrás. Isso fortaleceu o cenário de produção cultural pela presença das agremiações dos bois-bumbás Capricho e Garantido fomentando a consolidação de um rico ambiente de produção cultural com presença de estúdios musicais, escolas de arte, e a instalação do Liceu de Artes e Ofícios Cláudio Santoro.

Outro aspecto que aumenta a polarização de Parintins a seu entorno refere-se à presença de uma rede de empresas comerciais médias pertencentes à fração do capital mercantil (Silva, 2018), que interage com setores da economia popular conformando o Sistema Territorial Urbano-Ribeirinho (STUR), principal articulador da rede urbana sub-regional (Bartoli, 2018a). A aplicação do modelo STUR a Barreirinha será detalhada a seguir. A figura 1 apresenta os fluxos de embarcações regionais de pequeno e médio porte a partir de Parintins.

A coleta de dados relativa a Parintins que embasa a figura 1, entrevistou 114 proprietários de embarcações regionais médias pertencentes à economia popular. Contata-se que a rede local dos sujeitos, a partir de beiras de rio em bairros populares e área central (nós multireticulares), redesenha estratégias de deslocamentos para comunidades e municípios vizinhos, distribuindo bens industrializados e ao mesmo tempo trazendo para a cidade recursos naturais regionais, madeira, gado e diversos produtos agrícolas, complementando circuitos populares da economia urbana (comércio informal, feiras, pequenos açougues, etc.). Também abastecem setores do capital mercantil dominante da cidade como madeireiras, frigoríficos de pescados, matadouro, etc. (Bartoli, 2018a).

Observa-se na figura 1 que a cidade que está sob maior influência desse tipo de deslocamentos a partir de Parintins é Barreirinha. A centralidade é considerada enquanto nível de oferecimento de funções centrais por parte de uma determinada cidade para si mesma e para sua região, cujos bens e serviços centrais são oferecidos necessariamente em poucos lugares centrais (conforme indica a teoria de Christaller - 1968 apud Melo e Silva, 
2010). Com a crescente quantidade de pessoas acessando Parintins a partir de Barreirinha, as antigas embarcações de madeira foram sendo substituídas paulatinamente por lanchas de alumínio, denominadas localmente como "expresso" ou "a jato". Os percursos que eram realizados em quatro horas ou mais pelos barcos de madeira, foram reduzidos para uma hora ou uma hora e meia, dependendo da sazonalidade, como demonstra a figura 2. As doze lanchas que realizam tais percursos, revezam horários para atender a população possuindo mesmo trajeto. Na enchente as lanchas cortam caminho através dos canais que transbordam do lago das piranhas. Na vazante ("seca"), o caminho torna-se mais extenso sendo necessário seguir pelo Paraná do Limão até Barreirinha.

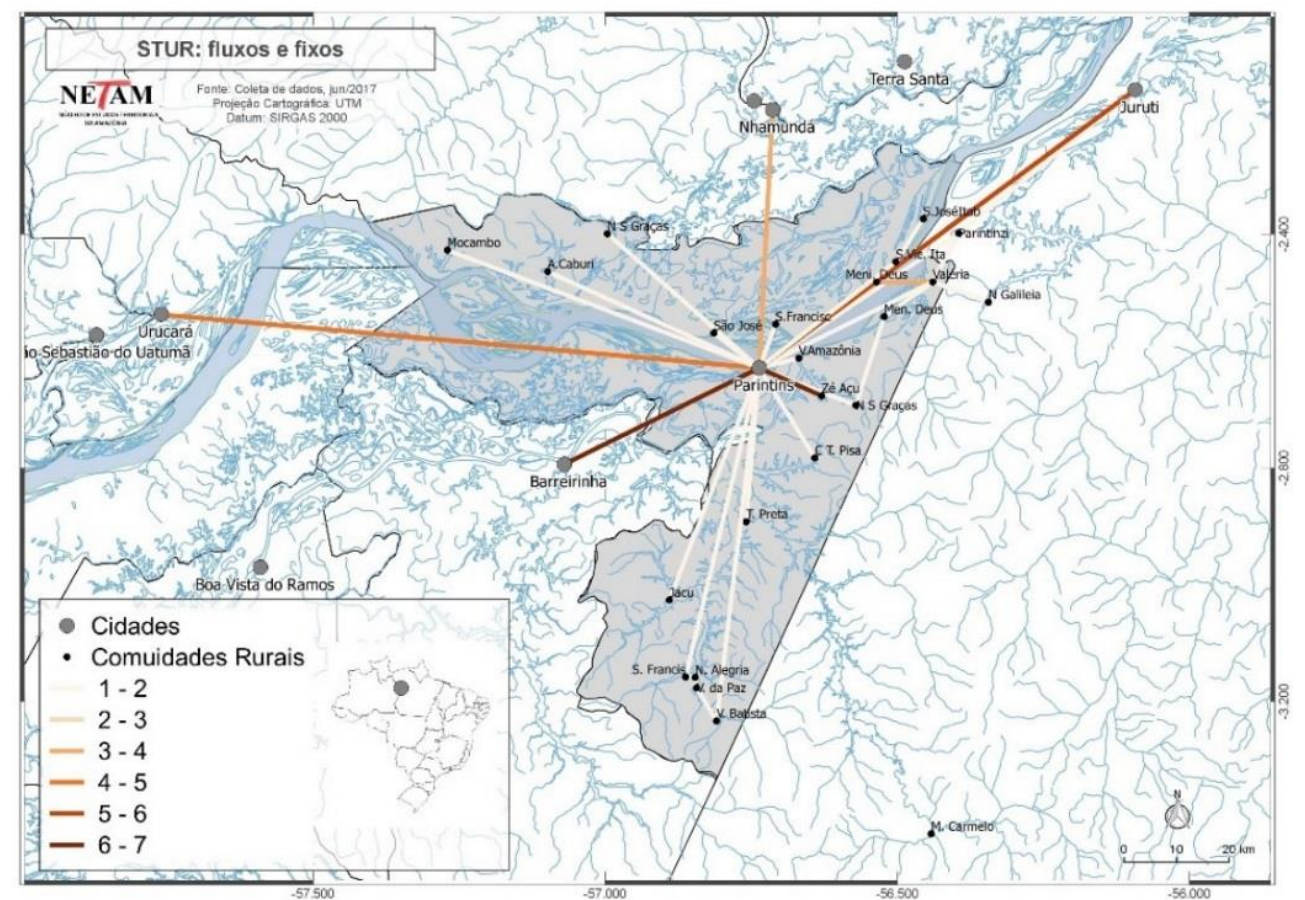

Figura 1 - Intensidade de fluxos semanais de embarcações de médio porte a partir de Parintins. Fonte: Elaboração própria através de dados coletados em jun/2017.

As transformações nesse tipo de transporte afetam a centralidade tanto de Barreirinha como das comunidades conectadas no trajeto. Não existem estradas que para tais conexões, sendo necessário que os fluxos restantes sejam feitos por outras "linhas" complementares.

Nota-se que Freguesia do Andirá perdeu centralidade, onde apenas a lancha Rainha da Amazônia realiza o trajeto da antiga sede para Parintins, e que, de acordo com o proprietário, os moradores das comunidades Paraíso e Barreira do Andirá acessam mais 
Parintins do que Barreirinha para consumo e serviços urbanos. As três lanchas Estrela e a lancha Coragem acessam ainda os distritos de Pedras e Terra Preta no Paraná do Ramos, que cresceram pelas posições privilegiadas.

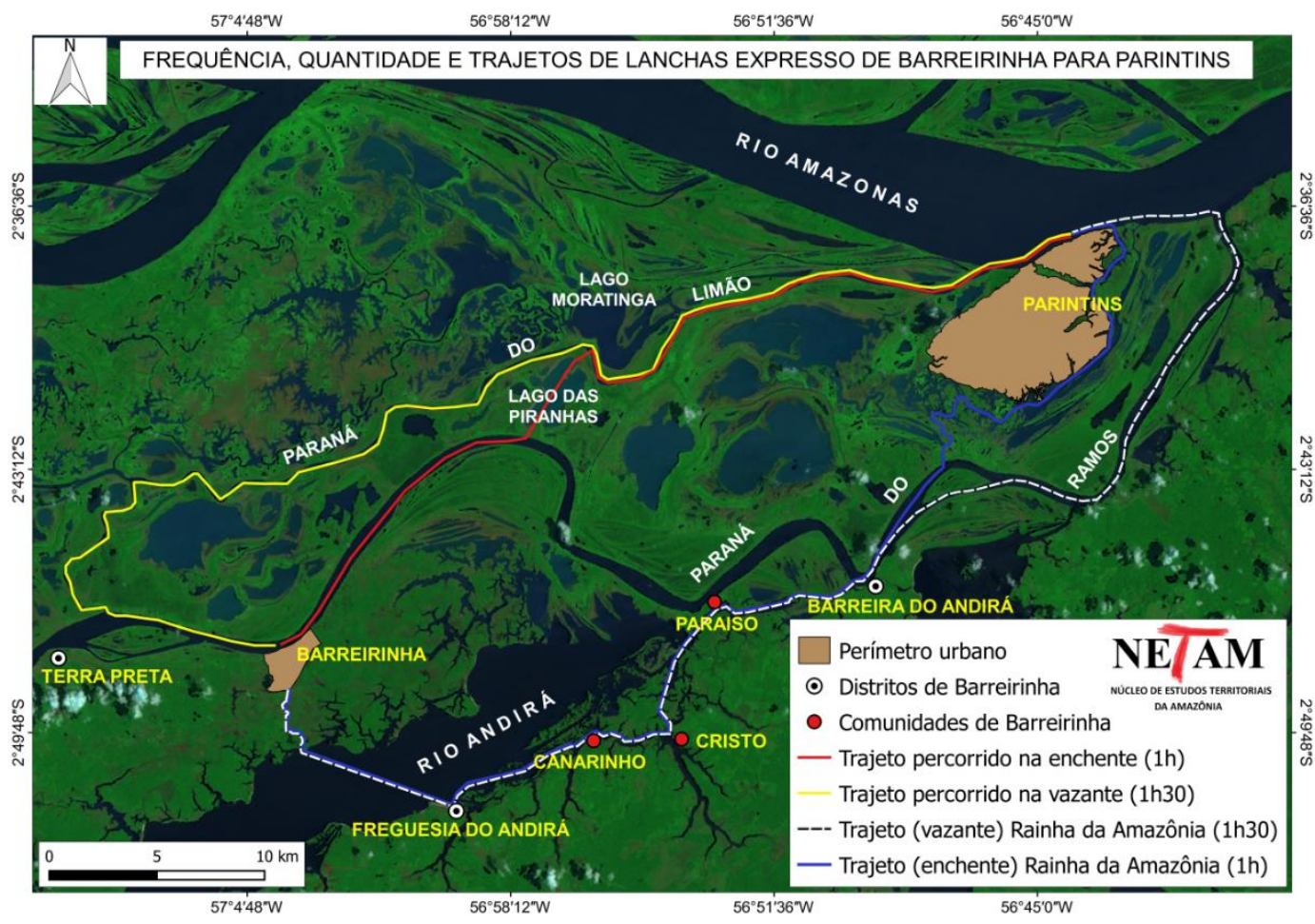

Figura 2 - Frequência, quantidade e trajetos de lanchas "expresso" entre Barreirinha e Parintins. Fonte: Elaboração própria através de dados coletados em abr/2019.

Tabela 2 - Percursos, quantidade e frequência das Lanchas expresso de Barreirinha-Parintins.

\begin{tabular}{|c|c|c|c|}
\hline Proprietário & Lanchas & Frequência / dia & Percurso fluvial \\
\hline Alciane & Estrela, Estrela II e Estrela III & Duas vezes por dia & $\begin{array}{c}\text { Pedras - Barreirinha - } \\
\text { Parintins }\end{array}$ \\
\hline Drico & Expresso Bae e Expresso Bae II & Uma vez por dia & Barreirinha - Parintins \\
\hline Zezinho & Zé Machado e Nova Zé & Dachado sim, dia não & Barreirinha - Parintins \\
\hline Hércules & Ajato Estrela e Ajato Estrela II & Uma vez por dia & Barreirinha - Parintins \\
\hline Ridete & Tarciele & Uma vez por dia & Barreirinha - Parintins \\
\hline Coragem & Luana & Uma vez por dia & Pedras - Barreirinha - \\
\hline Japoca & Rainha da Amazônia & Uma vez por dia & $\begin{array}{c}\text { Bae - Freguesia - Canarinho } \\
\text { - Cristo - Paraíso - Barreira } \\
\text { - Pin }\end{array}$ \\
\hline
\end{tabular}




\section{O Modelo STUR Aplicado a Barreirinha: Critérios de Análise, Resultados e Discussões.}

Os papeis e funções de Barreirinha foram afetados pelo processo acelerado de crescimento urbano e êxodo rural. Vínculos territoriais foram alterados, rompidos e, em muitos casos, recompostos pela maneira como sujeitos se articulam na cidade e "retornam a territórios". As características da economia popular que articulam novas mediações técnicas, culturais e políticas a partir da cidade, considerando também a coesão das redes de sujeitos em coletivos organizados como as cooperativas, associações e colônias de pescadores, são de suma importância para entender esses processos.

O STUR demonstra o comportamento espacial dos circuitos da economia popular inseridos em contexto específico, ocorrendo práticas espaciais cujo recorte analítico priorizou em estudos anteriores áreas de influência da cidade de Parintins. Apesar de privilegiar dinâmica sub-regional e intraurbana no modelo STUR, é preciso considerar dinâmicas transescalares para melhor detalhamento das complexas relações existentes com a rede urbana regional (com forte influência da metrópole Manaus em disputa com a rede urbana paraense), e escalas nacionais e globais. Tais conexões acabam sendo evidenciadas pelo tipo de bens industrializados que são distribuídos para os interiores.

Dinamizado por populações que se estabelecem nas cidades, moldando espaços intraurbanos e realizando intensos deslocamentos com as áreas de entorno, o papel mediador que o STUR abrange aparece em cinco vertentes que são apresentadas em Bartoli (2017; 2018a; 2018b): i) zonal e topológico: conectando a cidade por meio de redes temáticas a pontos diversos do entorno sub-regional através da navegação fluvial; ii) produção e configuração do espaço urbano em bairros oriundos de ocupações irregulares e de fragmentos do espaço intraurbano, constituindo fixos úteis para a navegação (beiras de rios populares, por exemplo); iii) econômico dual e complementar: sendo dinamizado principalmente pela economia popular mas em interação constante com as esferas de

\footnotetext{
${ }^{7}$ Em Bartoli (2017) demonstramos a multidimensionalidade presente em retornos a territórios de grupos urbanos como indígenas, pescadores, extrativistas e produtores de embarcações regionais. Tais "retornos" foram diferenciados pela maneira com que os grupos formularam projetos em coletivos organizados, alterando o modo como articularam territórios a partir da cidade: novas técnicas, mercados diferenciados atingidos, saltos escalares ou maior submissão ao mercado regional urbano.
} 
valorização do capital mercantil dominantes na cidade (saltos escalares ocorrem em relações diversas que ultrapassam a sub-região); iv) organizacional e institucional: outros tipos de coalizão de sujeitos ganham relevância (cooperativas, associações, colônias de pescadores, etc.), mediando ações que se desdobram em práticas sobre o território; v) simbólico-cultural: traços da cultura cabocla e ribeirinha, indígena ou de conhecimentos populares são absorvidos e resignificados pela inserção ao processo urbano.

Apresentamos na figura 3 a interação e composição entre os sistemas Territoriais. As circunferências pontilhadas (permeabilidades e interpenetrações) representam a abrangência dos sistemas e interações entre STUR e o sistemas dominante pertencente ao capital mercantil (Sistema Territorial Urbano-Fluvial - STUF), atingindo sistemas territoriais ribeirinhos com pouca interação com a cidade. Cada vez mais o STUR e o STUF se complementam, interpenetram. Isso ocorre com a aceleração dos processos de urbanização, intensificação da demanda por recursos naturais na cidade, e propagação do modo de vida e consumo urbano.

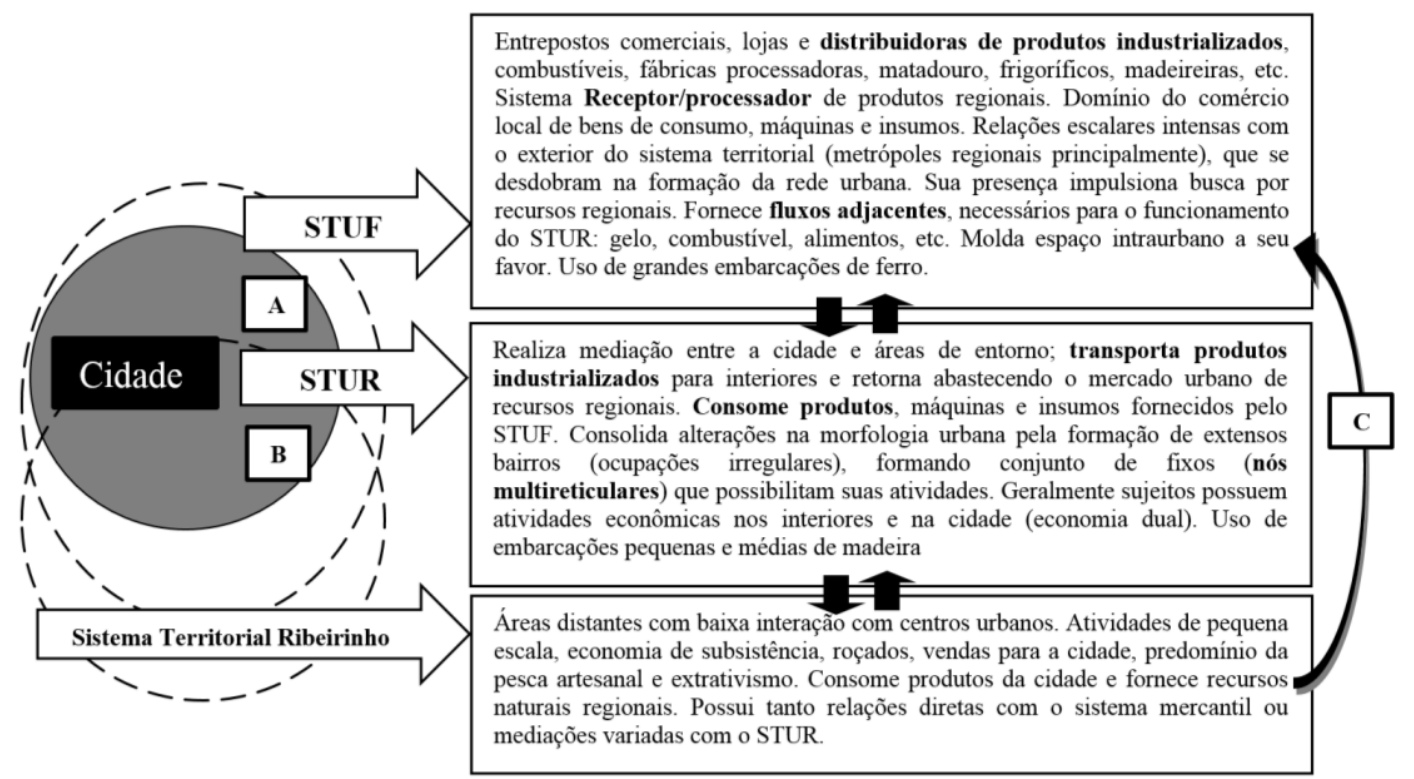

A - Tensões e conflitos: produção do espaço urbano (ênfase nas beiras de rio).

B - Hibridização: elaboração de soluções criativas e adaptações técnicas em instrumentos de trabalho, moradia, tipos de embarcações e outras formas espaciais perceptíveis em bairros populares.

C - Absorção direta de produtos regionais dos interiores pelo STUF com baixa mediação urbana.

Figura 3 - Conexões entre os sistemas territoriais mediados pela cidade.

Fonte: Bartoli, 2018a. 
Os dados obtidos através da aplicação de formulários a embarcações pequenas e médias pertencentes ao STUR, revelaram que, assim como em Parintins, em Barreirinha ocorre uma força centrífuga relacionada ao consumo, onde populações ao acessarem a cidade para realizar acessos às "benesses urbanas" (saúde, educação, comércio, etc.), acabam retornando com uma série de produtos industrializados adquiridos nos comércios locais, configurando aspectos do processo da urbanização extensiva (Monte-Mór, 1994). Nessa demanda de alimentos no mercado urbano cujo atendimento vem alterando cada vez mais itens da dieta regional, é marcante a presença crescente de conserva, frango congelado, embutidos e outros produtos industrializados (Moraes e Schor, 2010; Moraes, 2008; 2014).

A figura 4 demonstra essa tendência de consumo de produtos industrializados adquirido na cidade: eletrodomésticos, gasolina (para uso em embarcações, roçadeiras e motosserras), rancho (cesta básica) e estivas. A substituição paulatina dos fogões à lenha pelo uso de botijas é tímida ainda, mas notada pela presença das setas azuis do mapa. As comunidades do rio Andirá são abastecidas de carne bovina (setas rosas) pois não são áreas tradicionais de produção pecuária, que possui mais força nas comunidades ao norte do mapa no Paraná do Ramos (setas verdes na figura 5). A presença de ração animal também foi bastante notada, demonstrando prática da criação animal nas comunidades como fonte de proteína, principalmente o frango. A quantidade de embarcações entrevistadas, além de indicar o padrão de consumo/distribuição de produtos urbanos, nos serve ainda para salientar estratégias de vida dos moradores através dos deslocamentos.

Por fim, Barreirinha caracteriza-se por seu caráter funcional mais local, atendendo sua região imediata com alcance espacial "mínimo" considerando a escala municipal, mas atingindo longínquas comunidades da bacia do rio Andirá adentrando a Terra Indígena Andirá-Marau (etnia Sateré-Mawé). No quadro urbano sub-regional, a cidade possui centralidade baixa, limitando-se a atender seu entorno.

As permanências, quando tratamos do modelo STUR, estão associadas às longas e constantes trajetórias realizadas por transporte fluvial de setores populares, cultura herdada de ciclos econômicos passados, através do uso de lentas embarcações, fortalecendo o capital mercantil urbano. Tais comerciantes chamados de regatões eram muito presentes desde o ciclo da borracha no final do século XIX, realizando o intercâmbio entre áreas extrativas e os núcleos urbanos. As funções estritamente atreladas ao comércio 
que exerciam os regatões são dificilmente encontradas atualmente no baixo Amazonas, com raras ocorrências em comunidades e assentamentos humanos com alto grau de isolamento distantes de comunidades de acesso próximas par adquirir itens básicos de consumo.

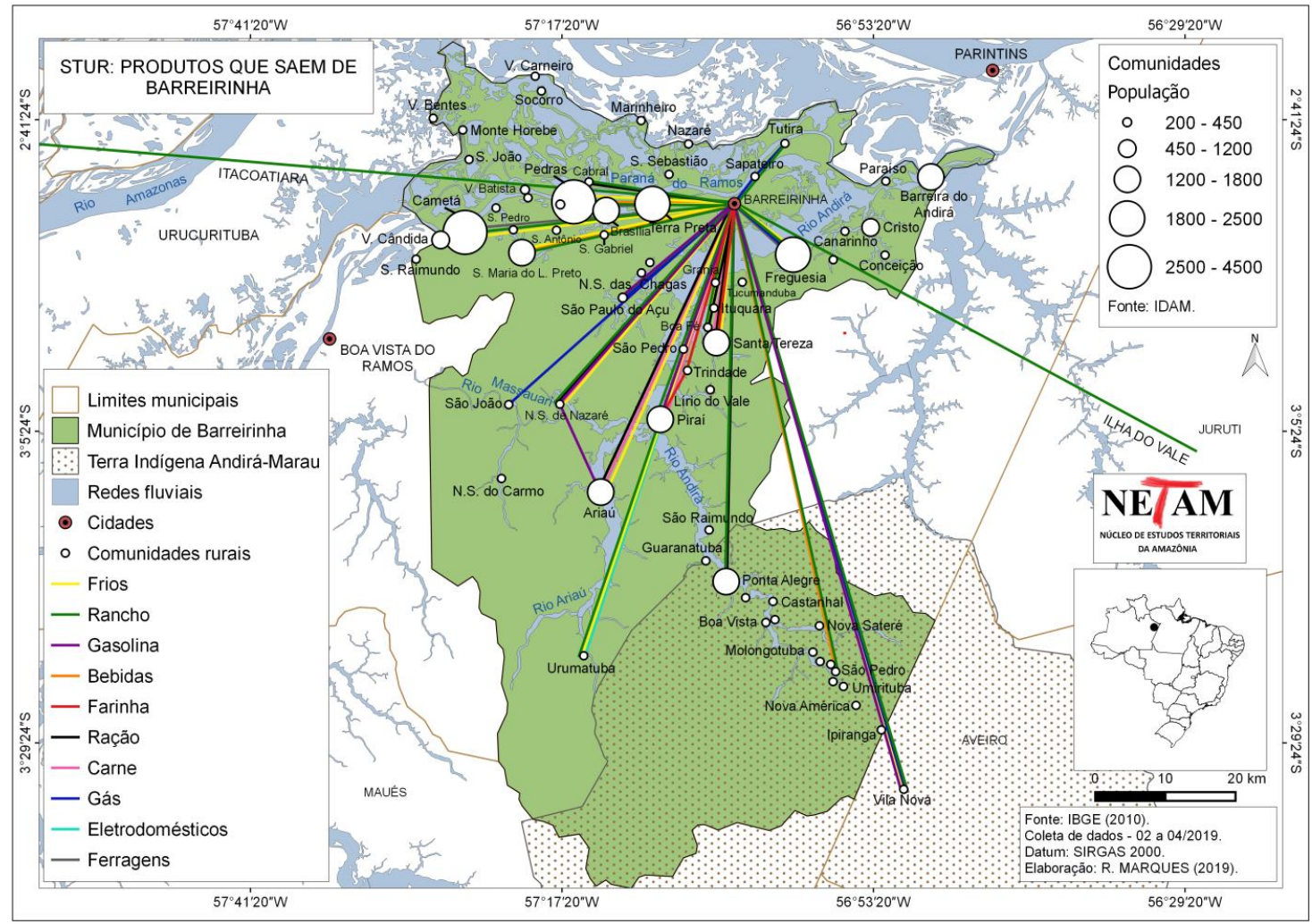

Figura 4 - Produtos que saem de Barreirinha em direção aos interiores.

Fonte: Elaboração própria através de dados coletados em abr/2019

A navegação hoje interliga o habitante produtor, extrator, pescador, comerciante, etc., que também vive na cidade, mas necessita retornar com frequência às comunidades de vínculos "umbilicais" que geralmente possuem longa trajetória de interação das famílias. A dualidade que alimenta esse tipo de economia popular que dinamiza o STUR é apresentada na Tabela 3 onde os proprietários de embarcações realizam atividades de serviços diversos na cidade necessitando de complementos de renda nos interiores. Sobre estas, destacamos o extrativismo, a pecuária de pequena escala, agricultura e criação de animais. 
Tabela 3 - Atividades econômicas dos proprietários de embarcações (cidade e interior).

\begin{tabular}{|c|c|c|c|c|c|c|c|c|c|c|c|}
\hline \multicolumn{4}{|c|}{ Atividade da cidade } & \multicolumn{4}{|c|}{ Atividade no interior } & \multicolumn{2}{|c|}{$\begin{array}{c}\text { Venda a } \\
\text { atravessadores }\end{array}$} & \multicolumn{2}{|c|}{$\begin{array}{l}\text { Frequência da } \\
\text { venda }\end{array}$} \\
\hline \multicolumn{2}{|c|}{ Atividade } & \multicolumn{2}{|c|}{$\begin{array}{c}\text { Possui } \\
\text { comércio na } \\
\text { cidade }\end{array}$} & \multicolumn{2}{|l|}{ Várzea } & \multicolumn{2}{|c|}{ Terra Firme } & Sim & Não & Mensal & Semanal \\
\hline Carpintaria & 01 & Sim & Não & Agricultura & 03 & Agricultura & 08 & \multirow{6}{*}{03} & \multirow{6}{*}{08} & \multirow{6}{*}{08} & \multirow{6}{*}{02} \\
\hline Pedreiro & 01 & \multirow{5}{*}{01} & & & & & & & & & \\
\hline $\begin{array}{c}\text { Serviços } \\
\text { gerais }\end{array}$ & 01 & & & Pecuária & 04 & Pecuária & 05 & & & & \\
\hline Vigia & 01 & & 17 & Extrativismo & 01 & Extrativismo & 04 & & & & \\
\hline Frete & 03 & & & $\begin{array}{c}\text { Criação de } \\
\text { aves }\end{array}$ & 02 & $\begin{array}{l}\text { Criação de } \\
\text { aves }\end{array}$ & 05 & & & & \\
\hline 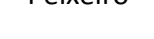 & & & & & & & & & & & \\
\hline
\end{tabular}

Fonte: Trabalhos de campo (04/2019).

O cenário mais preocupante encontrado nas pesquisas relativas a tais fluxos de embarcações do STUR, foi a enorme quantidade de madeira transportada dos interiores para a cidade. Como o Instituto de Desenvolvimento Agrário do Amazonas (IDAM) de Barreirinha confirmou, não há Plano de Manejo municipal, e as várias pilhas de madeira de lei foram notadas nas beiras de rio da cidade durante os trabalhos de campo, se deduz que essa atividade ilegal é uma das mais intensas hoje no município. Essa é uma questão chave para entender a inserção de Barreirinha na hierarquia urbana sub-regional, pois passa a fornecer enorme quantidade de madeira ilegal também para Parintins, como constatamos em trabalhos de campo presentes em Bartoli (2017). As setas vermelhas na figura 5 e os diversos relatos dos agentes receptores na cidade confirmam tal intensidade de extração. Lembramos aqui que essa característica de extração predatória de madeira está presente em todos os municípios do baixo Amazonas, variando na intensidade e demanda urbana de cada situação. Isso reforça a tese apresentada no primeiro item do texto sobre o descaso de décadas com a economia interiorana pós implantação do modelo ZFM. 


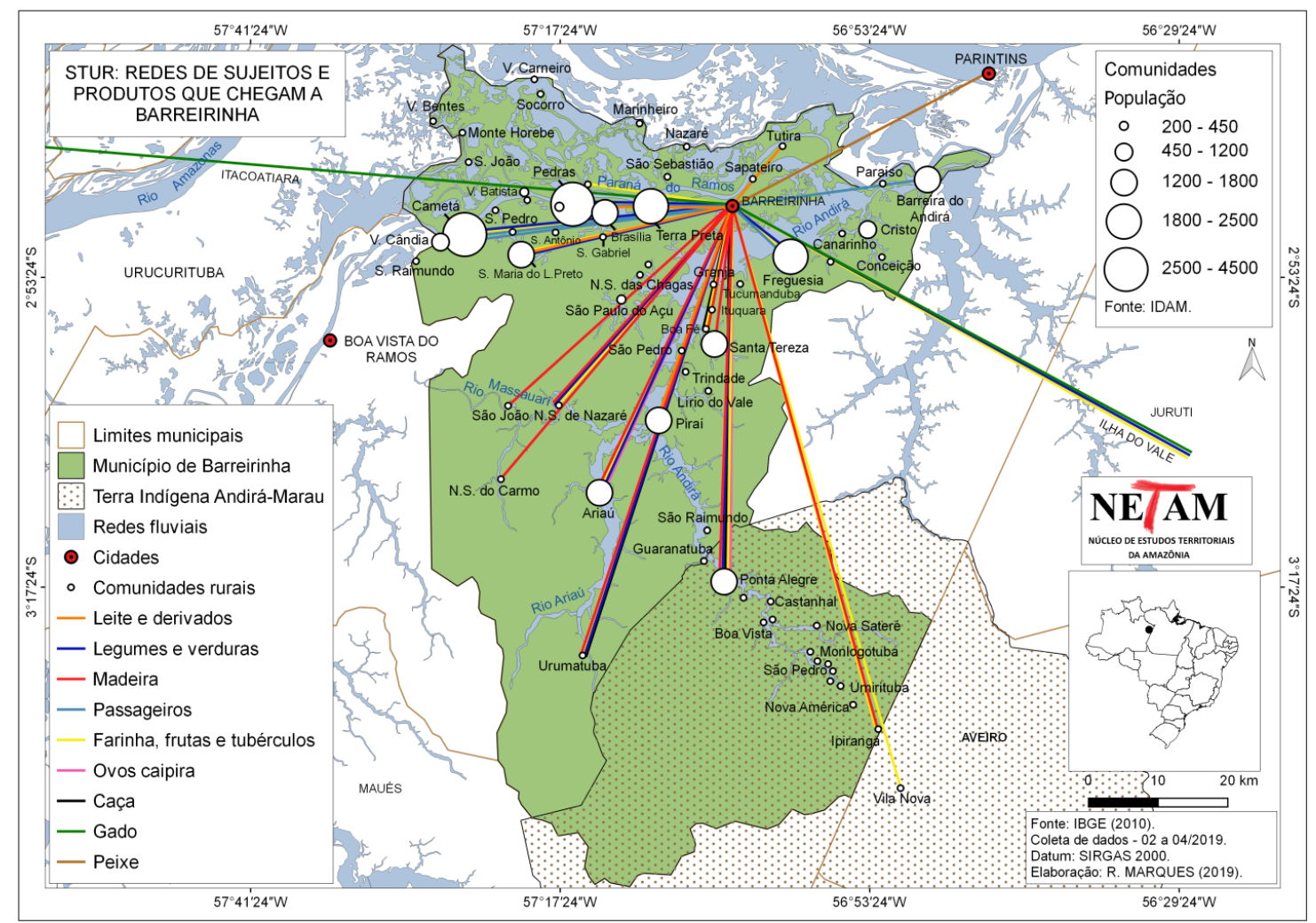

Figura 5 - Produtos que chegam a Barreirinha dos interiores.

Fonte: Elaboração própria através de dados coletados em abr/2019

Existe apenas um estaleiro naval de pequeno porte na cidade que fabrica poucas embarcações no ano (média de quatro). Assim, a maior demanda de madeira processada pela cidade ocorre nas movelarias e pequenas serrarias. De acordo com o presidente da Associação de moveleiros, vinte pequenas unidades processam a madeira, sendo cinco apenas cumprindo função de serrarias e as demais fabricando móveis. Não há estufa para secagem correta da madeira, o que denota que o setor ainda é carente de melhorias técnicas.

O consumo de madeira por movelaria é em média de 4 metros cúbicos por cada pequena unidade produtiva. As espécies mais consumidas são o angelim, a cupiúba, marupá, muiracatiara e sapateiro ${ }^{8}$. O destino da produção local é metade absorvido por Manaus, cujas compras se concentram em esquadrias (portas, janelas, basculantes, etc.) e o restante absorvido pelo mercado local, adicionando produção de móveis domésticos a essas vendas locais.

\footnotetext{
${ }^{8}$ Temos notado que os nomes populares de madeiras usadas nas cidades variam no baixo Amazonas, o que traz certa dificuldade em imprecisão para catalogar a pressão sobre determinadas espécies.
} 
Segundo os entrevistados, a união entre os moveleiros para a formação de um coletivo organizado ainda é baixa, com raras reuniões e fraca coesão do grupo. A primeira reunião com apoio institucional para formação de uma cooperativa estava agendada para o mês de abril de 2019, com apoio de um técnico do Instituto de Desenvolvimento Agroflorestal do Amazonas. As características das movelarias são muito semelhantes entre as cidades do baixo Amazonas, mesmo comparadas as de Parintins que contam com maior apoio e densidade institucional: pequenas unidades com maquinário antigo e baixa inovação no designer dos móveis. Em Barreirinha algumas se localizam nos entornos do porto popular do Pucu, pela facilidade do desembarque diário de madeira e por ficar menos visível por estarem nos "fundos" da cidade, que perde contato via rio nas secas, dificultando ainda mais qualquer tipo de fiscalização. Por parte dos moveleiros entrevistados, não houve qualquer tipo de problema em afirmar que a maioria da madeira é retirada sem planos de manejo, conferindo certo aspecto de normalidade dessa atividade no relatos. Nesse sentido, a percepção sobre a ilegalidade parece estar diluída em uma das práticas mais antigas dos moradores locais, com raras notícias de fiscalização ou aplicação de multas pelos órgãos ambientais. Não notamos qualquer comentário entre os que transportam e os que compram a madeira que indicasse preocupação ambiental sobre o estoque madeireiro, que cada vez mais tem sido extraído em localidades longínquas.

Nos bairros recentemente formados por ocupações irregulares nas periferias é perceptível a recente absorção de madeira pela cor ainda não escurecidas das tábuas (figura 6). Por serem bairros sujeitos à inundação localizados em várzeas, não há possibilidade de se construir moradias com lajes de concreto devido alto custo. Um dos entrevistados afirmou que depois das últimas grandes cheias acima da média, muitas casas tiveram que ser reconstruídas, necessitando soerguer ainda mais o assoalho da distância do solo. As grandes cheias em cidades com sítios inundáveis afetam a qualidade de vida das populações menos favorecidas, alimentando o mercado local ilegal de madeira, apesar de considerarmos um uso socialmente necessário. O limite entre legalidade e ilegalidade se dissolve neste caso, pois tais populações acabam imprimindo um uso social de extrema necessidade na busca do direito a uma moradia na cidade. 


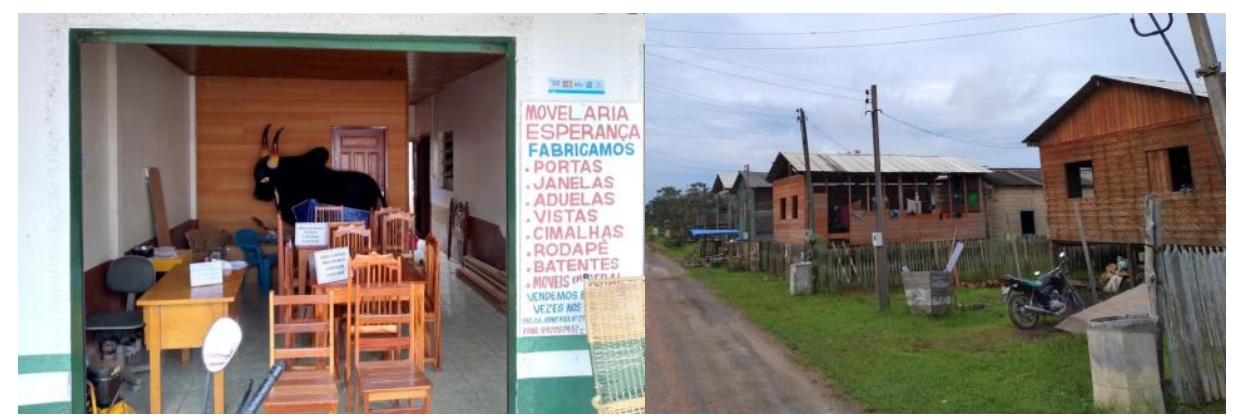

Figura 6 - Loja da fábrica de uma das movelarias e moradias populares (palafitas) em bairro irregular sujeito à inundação.

Fonte: Recolha própria através de dados coletados em abr/2019

O tipo de dinâmica logística entre produtos que a cidade distribui e os que chegam, nos fornece boas indicações das territorialidades que compõem o papel do STUR. Mais do que logísticos, indicam outras territorialidades e ritmos. Pela escassez de dinâmica econômica urbana (rever tabela 1 - PIB per capta e pessoal ocupado), o uso das embarcações torna-se elemento complementar, tanto para extração de produtos regionais, pesca, produção agrícola, etc., como cumprindo função de moradia. Nesses constantes deslocamentos, as beiras de rios repletas de embarcações acabam sendo disputadas por agentes diversos.

\section{Considerações Finais}

Pela disparidade populacional e econômica em relação à capital Manaus, diagnósticos sobre cidades pequenas no Amazonas podem se tornar desafiadores. No presente texto buscamos evidenciar que o sítio urbano possui condicionantes na dinâmica das redes urbanas (tecidas pelo STUR e STUF). A estruturação dessas redes mais recentes se sobrepondo aquela preexistente (calha do rio Andirá - antiga sede e área de influência direta), reposiciona a centralidade comercial de Barreirinha sobre comunidades que abastecem a cidade com produtos variados.

No caso de cidades que possuem sítios urbanos que condicionam dinâmicas fluviais e ribeirinhas, centrais para formação da situação em Barreirinha, os papeis na Divisão Territorial do Trabalho são estruturados pelo tipo de circulação em duas calhas de rios distintas. O rio Andirá, local da antiga sede é mais "fechado", com sua rede urbana voltada para a mediação e mercados de Barreirinha, possuindo baixa complexidade de funções 
produtivas e comerciais, mas possuindo enorme extração de madeira, que chega atingir mercados de outras cidades. Já a rede urbana do Paraná do Ramos, local da sede atual, é mais "aberta" e dinâmica, recebendo fluxos da metrópole Manaus a oeste e da rede urbana paraense a leste, condicionando ainda Barreirinha a ser polarizada por Parintins, cidade média de responsabilidade territorial. Os núcleos menores no Ramos (distritos) são os que mais cresceram nos últimos anos: Pedras, Cametá e Terra Preta, cujos papeis serão descritos nas próximas etapas da atual pesquisa.

Ausência de agregação de valor aos produtos exportados no baixo Amazonas merece atenção urgente (pescado e madeira principalmente, indicados em Bartoli - 2017, 2019), fato presenciado em Barreirinha no caso da madeira. A capacidade de ordenamento das relações territoriais da cidade fica comprometida, com ausência de planos de manejo, baixa presença e atuação de instituições locais e insuficiente organização do setor moveleiro. Portanto, a cidade apesar de pequena, é responsável por enorme impacto ambiental.

Barreirinha cumpre assim, padrões de circulação e extração de excedentes ligados ao processo de urbanização, pela maneira com que redes de sujeitos e suas práticas territoriais reinserem os papeis do núcleo urbanos numa nova divisão territorial do trabalho: intensa distribuição de produtos industrializados para os interiores condicionada à navegação (STUF necessitando do STUR), com uso de comunidades para posterior redistribuição para os longínquos assentamentos humanos do alto curso dos rios da sub-região.

A caracterização do município de Barreirinha no contexto nacional frente a nossa hipótese fica latente na maneira como se expressam as principais demandas da população, demonstrando ampliação qualitativa e quantitativa do consumo urbano através da dinâmica do STUR.

\section{Referências}

Andrade, A. C.. Sinopse Histórica do Município de Barreirinha. Manaus: Editora Sergio Cardoso \& CIA. LTDA, 1960.

Bartoli, E. O Retorno ao Território a partir da cidade: Sistemas Territoriais Urbano-Ribeirinhos em Parintins (AM). Presidente Prudente: PPGG / UNESP, 2017 (Tese de Doutorado).

Bartoli, E. Cidades na Amazônia, Sistemas Territoriais e a Rede Urbana. Mercátor, v. 17, e17027, p. 1-16, 2018a:. 
Bartoli, E. Entre o Urbano e o Ribeirinho: Territorialidades Navegantes e Sistemas Territoriais em Parintins (AM). Espaço Aberto, PPGG - UFRJ, Rio de Janeiro, v. 8, n.2, p. 169-185, 2018b.

Bartoli, E. Territorialidades Urbano-Ribeirinhas: o Sistema Territorial pesqueiro de Parintins (AM). GeoNorte, v.13, 2019.

Bartoli, E. Schor, T. Oliveira, J.A., Cidades Médias na Amazônia: ampliando percepções sobre a responsabilidade territorial de Parintins (AM). Terra Plural, 2019.

Becker, B. K. A Geopolítica na virada do Milênio: Logística e Desenvolvimento Sustentável. In: I. E. de Castro. Geografia e política: Território, escalas de ação e instituições. Rio de Janeiro: Bertrand Brasil, 2005

Becker, B. K. O Uso Político do Território: questões a partir de uma visão do Terceiro Mundo. in: B. K. Becker, R. H. Costa, C. D. B. Silveira (orgs.). Abordagens Políticas da Espacialidade. Rio de Janeiro: UFRJ, 1974.

Becker, B. K. Amazônia. São Paulo: Ed. Ática, 1990. (Série Princípios).

Becker, B. K. Amazônia: mudanças estruturais e urbanização. in: Gonçalves, Maria Flora et al. (org). Regiões e Cidades, Cidades nas Regiões: o desafio urbano-regional. São Paulo: Ed. UNESP/ANPUR, 1998.

Becker, B. K. A Urbe Amazônida. Rio de Janeiro: Garamond, 2013.

Corrêa, R. L. . A Periodização da Rede Urbana na Amazônia. in: Corrêa, R. L. Estudos sobre a rede urbana. Rio de Janeiro: Bertrand Brasil, 2006.

Brandão, C. A. . Território e Desenvolvimento: as múltiplas escalas entre o local e o global. Campinas: Editora da Unicamp, 2007

Browder, J.O \& Godfrey, B.J. Cidades na Floresta. Manaus: EDUA, 2006.

Christaller, W. Central places in Southern Germany. Englewood Cliffs: Prentice Hall, 1968.

Compans, R. Empreendedorismo Urbano, entre o Discurso e a Prática. São Paulo: UNESP, 2005.

Endlich, A. M. Pensando os papéis e significados das pequenas cidades. São Paulo: Ed. Unesp, 2009.

GEORGE, Pierre. Geografia Urbana. São Paulo: Difel,1983.

Machado, L. O. A Urbanização e Mercado de Trabalho na Amazônia Brasileira. Cadernos do IPPUR, 1, 1999, pp. 109-138.

Monte-Mór, R.L. A Urbanização Extensiva e Lógica de Povoamento. In M. Santos, et. al. (orgs.) Território, globalização e fragmentação. São Paulo: Hucitec/Anpur, 1994 (pp. 169-181)

Moraes, A. O. Peixe, farinha e frango congelado: rede urbana e alimentação na calha do rio Solimões. In: Anais do XV Encontro Nacional de Geógrafos (ENG). São Paulo: 2008.

Moraes, A. O. Peixes, redes e cidades: aspectos socioambientais da pesca comercial de bagres no Médio e Alto Solimões - AM. 2012. 140 f. Dissertação (Mestrado em Ciências do Ambiente e Sustentabilidade na Amazônia) Universidade Federal do Amazonas, Manaus, 2012.

Moraes, A. O. Embalando Mercados em Redes Urbanas: alimentação e pesca articulando cidades na Amazônia brasileira. in: Schor, T. (org.). Dinâmica Urbana na Amazônia - vol. 1. Manaus: Valer, 2014.

Moraes, A. O.; Schor, T.; Alves-Gomes, J. O Mercado de Bagres e a Configuração da Rede Urbana no Alto e Médio Solimões, Amazonas, Brasil. Caderno Prudentino de Geografia. v.1, n.32, p. 93-110, 2010.

Oliveira, J. A.; Schor, T. Reflexões Metodológicas sobre o Estudo da Rede Urbana no Amazonas e Perspectivas para a Análise das Cidades na Amazônia Brasileira. ACTA Geográfica, Ed. Esp. Cidades na Amazônia Brasileira, p. 15-30, 2011.

Rondinelli, D. A. Equity, growth and development. Journal of the American Planning Association, v. 51, n. 4, p. 434-448, 1985a.

Santos, M. O Espaço Dividido: Os Dois Circuitos da Economia Urbana dos Países Subdesenvolvidos. Rio de Janeiro: Francisco Alves, 1979.

Santos, M. Silveira, M. L. Brasil: território e sociedade no limiar do século XXI. Rio de Janeiro: Record, 2003. 
Schor, T.; Oliveira, J. A. Parintins: a geografia da saúde na formação da cidade média de responsabilidade territorial. In: E. Bartoli et al. Parintins: Sociedade, Territórios \& Linguagem. Manaus: EDUA, 2016, p. 35-58.

Schor, $\mathrm{T}$ et al. Apontamentos metodológicos sobre o estudo de cidades e de rede urbana no Estado do Amazonas, Brasil. PRACS: Revista Eletrônica de Humanidades do Curso de Ciências Sociais da UNIFAP https://periodicos.unifap.br/index.php/pracs ISSN 1984-4352 Macapá, v. 9, n. 1, p. 09-35, jan./jun. 2016

Schor, T.; Marinho, T. P. Ciclos econômicos e periodização da rede urbana no Amazonas - Brasil: as cidades Parintins e Itacoatiara de 1655 a 2010. Revista do Instituto de Estudos Brasileiros. Brasil, n. 56, p. 229-258, jun. 2013.

SILVA. S. B. de M. Cidades pequenas e médias: reflexões teóricas e aplicadas. In: Cidades médias e pequenas: teorias, conceitos e estudos de caso. / Diva Maria Ferlin Lopes, Wendel Henrique (organizadores). - Salvador: SEI, 2010. 250 p. il. (Série estudos e pesquisas, 87).

Sposito, E. S. ; Jurado da Silva, P. F. Cidades Pequenas, perspectivas teóricas e Transformações Socioespaciais. Jundiaí: Paco editorial, 2013.

Silva, F. Capital Mercantil, Transportes Fluviais e a Rede Urbana Sub-Regional de Parintins - AM. Parintins-AM, 2018. Monografia de Conclusão de Curso Licenciatura em Geografia) - Universidade do Estado do Amazonas, UEA/CES/Parintins, 2018.

SUFRAMA. Relatório de Gestão. Ministério do Desenvolvimento Indústria e Comércio Exterior, 2007. Disponível em http://www.suframa.gov.br/suframa relatorio de gestao.cfm

Wallerstein, I. The relevance of the concept of semiperiphery to the analysis of Southern Europe. In: Arrighi, G. (ed.) Semiperipheral development: the politics of Southern Europe in the twentieth century. Beverly Hills: Sage publications, 1985.

Trindade JR, S. C. C. Diferenciação territorial e urbanodiversidade: elementos para pensar uma agenda urbana em nível nacional. Cidades, Presidente Prudente, Grupo de Estudos Urbanos, v.7, n.12, p.227-225, 2010.

Vidal de La Blache, P. La France de l' Est. Paris: Armand Colin, 1920.

Vicentini, Y. Cidade e História na Amazônia. Curitiba: UFPR, 2004. 